Proceedings

\title{
Monitoring of Native and Introduced Ambrosia Beetles (Curculionidae: Scolytinae) With Two Different Lures ${ }^{\dagger}$
}

\author{
Ferenc Lakatos ${ }^{1, *}$, Katalin Tuba ${ }^{1}$ and Darek Czokajlo ${ }^{2}$ \\ 1 Institute of Forest and Natural Resource Management, Faculty of Forestry, University of Sopron Bajcsy- \\ Zsilinszky u. 4, H-9400 Sopron, Hungary; lakatos.ferenc@uni-sopron.hu (F.L.), tuba.katalin@uni-sopron.hu \\ (K. T.) \\ 2 Alpha Scents Inc., 360 S. Sequoia Parkway, Canby, Oregon 97013, United States; darek@alphascents.com \\ * Correspondence: lakatos.ferenc@uni-sopron.hu \\ + Presented at the 1st International Electronic Conference on Entomology (IECE 2021), 1-15 July 2021; \\ Available online: https://iece.sciforum.net/.
}

\begin{abstract}
Two lures (REDBAY \& AMBRO) developed for the monitoring of an introduced/invasive species (Redbay ambrosia beetle (Xyleborus glabratus)) were tested in semi-natural forests in Hungary. Three sites were selected, and one-one traps with the different lures each were set up and controlled regularly. Altogether more than 12 thousand ambrosia beetles were caught. The lure blend AMBRO proved to be more effective (approx. 11,000 beetles) in compare to REDBAY blend (approx. 1,000) beetles. Both native and introduced ambrosia beetles were captured, however, the invasive Xylosandrus germanus was the most dominant species (approx. 10,600 specimens). Other ambrosia beetles of the genus Trypodendron, Xyleborus, Xylosandrus, Xyleborinus and Platypus were also present.
\end{abstract}

Keywords: Trypodendron; Xyleborus; Xylosandrus; Xyleborinus; invasive species monitoring

Citation: Lakatos, F.; Tuba, K.; Czokajlo, D. Monitoring of Native and Introduced Ambrosia Beetles (Curculionidae: Scolytinae) With Two Different Lures, in Proceedings of the 1st International Electronic Conference on Entomology, 1-15 July 2021, MDPI: Basel, Switzerland, doi:10.3390/IECE-10376

Published: 30 June 2021

Publisher's Note: MDPI stays neutral with regard to jurisdictional claims in published maps and institutional affiliations.

Copyright: (c) 2021 by the authors. Submitted for possible open access publication under the terms and conditions of the Creative Commons Attribution (CC BY) license (http://creativecommons.org/licenses /by/4.0/).

\section{Introduction}

Damages caused by scolytid beetles (Curculionidae, Scolytinae) have increased significance in recent decades both in Europe and North America. Besides of the problems caused by native bark beetles (e.g., Ips typographus in Europe or Dendroctonus ponderosae in North Amerika) the effect of introduced/invasive ambrosia beetles shows an increasing trend as well. Except the last few years ambrosia beetles were less investigated and only with the increase of their introduction and damage caused to natural or even urban environments highlighted the need for more detailed analyses. Investigations have been conducted on various traps and lures for early detection methods in and around major transportation hubs (ports, airports, ...) and major timber processing companies. Although the major target group of these investigations are introduced and/or invasive species, less is known on their effect on the native ambrosia beetle fauna.

\section{Materials and Methods}

In 2019 two Theysohn traps (dry) were set up in an oak-beech-pine-spruce forest (S1) in the mountains of Sopron (set up 23/04/2019). In 2020 two additional sites were selected, one in a broadleaved dominated (S2) and another one in a conifer dominated (S3) forest. This year Econex wet traps were used (set up 11/03/2020) to avoid the predation on the trap captures by the clerid beetles. All pairs of the traps were set with the two types of lures for the redbay ambrosia beetle Xyleborus glabratus: REDBAY \& AMBRO. 
Traps were controlled 9 times in 2019 and 21 times in 2020 from setup until September. Trapped beetles were dried, sorted and identified, in case of bark and ambrosia beetles to the species level. Other beetle species were also sorted out and identified to the genus level at least.

The statistical analysis of the raw data is still in progress.

\section{Results}

In 2019 the two Theysohn traps caught altogether 8450, while in 2020 the three pairs of Econex traps caught altogether 3796 ambrosia beetles (Table 1). Both native and introduced ambrosia beetles were captured, however, the invasive Xylosandrus germanus was the most dominant species (approx. 10,600 specimens), followed by the native Xyleborinus saxesenii with a much lower number of individuals (1075). Other ambrosia beetles of the genus Trypodendron, Xyleborus, Xylosandrus, and Platypus were also captured in lower numbers.

Because of the surpassing number of Xylosandrus germanus individuals in the traps in 2019 we made the evaluation and statistical analysis for the trap captures of 2020 only.

Table 1. Number of ambrosia beetles caught with the different lures in 2019 and 2020.

\begin{tabular}{|c|c|c|c|c|}
\hline \multirow{2}{*}{ Species } & \multicolumn{2}{|c|}{2019} & \multicolumn{2}{|c|}{2020} \\
\hline & RED & AMB & RED & AMB \\
\hline Trypodendron domesticum & - & - & 4 & - \\
\hline Trypodendron lineatum & - & 1 & 8 & 8 \\
\hline Trypodendron signatum & - & - & 44 & 10 \\
\hline Xyleborus dispar & 3 & 1 & 37 & 19 \\
\hline Xyleborus dryographus & - & - & 12 & 39 \\
\hline Xyleborus monographus & 14 & 21 & 181 & 36 \\
\hline Xyleborinus saxesenii & 17 & 234 & 207 & 617 \\
\hline Xylosandrus germanus & 318 & 7840 & 168 & 2398 \\
\hline Platypus cylindrus & - & 1 & 1 & 7 \\
\hline SUM & 352 & 8098 & 662 & 3134 \\
\hline
\end{tabular}

In 2020 the lure AMBRO caught altogether 3134 individuals of 8 species, while the lure REDBAY 662 individuals of all 9 species. There are large differences also among locations. The site S1 (oak-beech-pine-spruce forest) showed the highest numbers (2344) followed by the broadleaves dominated site (S2 with 1264 specimens). The conifer dominated site (S3) showed the lowest captures (179 specimens).

We observed differences in the flight periods of the different species as well. Trypodendron signatum showed a distinct spring and summer generatiosn, which were not present in the other two Trypodendron species. Similar pattern with a stronger summer generation was observed for Xyleborus dispar as well. Xyleborus dryographus showed a typical one (summer)generation pattern, while Xyleborus monographus, Xyleborinus saxesenii and Xylosandrus germanus showed a more or less continuous presence across the entire vegetation period.

\section{Discussion}

The lure blend AMBRO proved to be more effective (approx. 11,000 beetles) in compare to REDBAY (approx. 1,000) beetles. 
Author Contributions: Conceptualization, F.L. and D.C.; methodology, F.L.; software, K.T.; validation, F.L., K.T. and D.C.; formal analysis, K.T.; investigation, F.L.; resources, F.L. and D.C.; data curation, F.L.; writing - original draft preparation, F.L.; writing - review and editing, D.C.; visualization, K.T.; supervision, F.L.; project administration, F.L.; funding acquisition, F.L. All authors have read and agreed to the published version of the manuscript.

Funding: Please add: This research was funded by EFOP-3.6.2-16-2017-00018 program at the University of Sopron.

Data Availability Statement: Please refer to suggested Data Availability Statements in section "MDPI Research Data Policies" at https://www.mdpi.com/ethics.

Acknowledgments: In this section, you can acknowledge any support given which is not covered by the author contribution or funding sections. This may include administrative and technical support, or donations in kind (e.g., materials used for experiments).

Conflicts of Interest: The authors declare no conflict of interest. 